\title{
Total Phenolic Content, Microbial Content and Sensory Attributes Evaluation of White Soft Cheese Incorporated With Mint (Mentha Spicata) Leaf Extract
}

\author{
Abdulaal F. Fezea ${ }^{1}$, Hyder N. Al-Zobaidy ${ }^{1}$, Muhsin F. Al-Quraishi ${ }^{1}$ \\ ${ }^{I}$ Department of animal production, College of Agriculture, University of Wasit, Wasit, Iraq.
}

\begin{abstract}
Mint herb (Mentha spicata L.) is widely known as a good source of bioactive compounds. Therefore, this study aimed to use the aqueous mint leaf extract (AMLE) in white soft cheese processing and to evaluate the total phenolic content, microbial content and sensory attributes of the resulting cheese. Dried mint leafs were extracted with water to obtain an aqueous extract. Prior to white cheese processing, different concentrations (1, 2 and 3\%,v/v) of AMLE were added to the milk. White soft cheese containing AMLE had significantly higher phenolic compounds than the control cheese and the highest phenolic content (96.0 mg GAE / $100 \mathrm{~g}$ cheese) was found in white soft cheese samples containing 3\% of AMLE. The results of microbial analysis showed that the microbial growth in white soft cheese tends to decrease with increasing AMLE concentration and no microbial growth was observed in white soft cheese containing 3\% of AMLE. The sensory evaluation revealed that the addition of AMLE had no significant effect on the overall acceptance of all types of cheese manufactured.
\end{abstract}

Keywords: Mint; white soft cheese; phenolic compounds; microbial content; sensory evaluation.

\section{Introduction}

Phenolic compounds are one of the most abundant groups of secondary metabolites found in the plant kingdom they can act as protective agents, inhibitors, natural animal toxicants and pesticides against attacking many organisms such as herbivores, nematodes, phytophagous insects, and fungal and bacterial pathogens. The aroma and pigmentation of phenolic compounds can attract symbiotic microbes, pollinators and animals that disperse fruits [1]. Phenolic compounds are commonly found in both edible and nonedible plants. Recently the phenolic compounds take much interest as bioactive components of food; they have been reported to have multiple biological effects, including antioxidant activity. The roles of fruit, herbs, cereals, vegetables and red wine in disease prevention have been recognized, partly the antioxidant properties of their polyphenols (vitamins $\mathrm{E}$ and $\mathrm{C}$, and the carotenoids). Current studies have shown that many dietary phenolic compounds derived from plants are more effective antioxidants in vitro than vitamins $\mathrm{E}$ or $\mathrm{C}$, and therefore influence significantly to the protective effects in vivo [2].

Phenolic compounds improve the quality and nutritional value of food because they delay oxidative degradation of lipids, maintenance of health and protection from coronary heart disease and cancer. The importance of the antioxidant compounds raised the interest among food manufacturers to move toward functional food with specific health effects [3], [4]. The addition of antioxidant compounds to liquid whey prior to further processing found to be beneficial to prevention of flavor deterioration. The antioxidants minimize Lipid oxidation products which they are primary contributors to whey ingredient off-flavors [5]. Up to now herbs have been used as food flavorings and food preservatives for its medicinal and antiseptic properties that are derived from their antimicrobial and antioxidant components [6]. It was demonstrated that the natural source of antioxidants showed good antioxidant level after their fortification in dairy product. Among the several herbs mint (Mentha spicata L.) is well-known item in our daily diet. Several studies have represented that mint is a good source of natural antioxidant. However, combination of mint with other natural sources produced good synergistic action on the antioxidant level of dairy products [7].

A previous study demonstrated that the addition of Mentha spicata essential oil to traditional Lighvan cheese was effective against Listeria monocytogenes. Moreover, with increasing salt water concentration, the antibacterial effect of the M. spicata essential oil increased [8]. The study of addition mint leafs extract to white soft cheese processing has not yet been fully investigated. As white soft cheese is consumed widely in most countries, the objective of this research would be proofed of the influence of usage of mint leafs as an antimicrobial food additive in white cheese processing. 


\subsection{Materials}

\section{Materials And Methods}

Fresh cow's milk collected from Kut region in Wasit province (south-east of Iraq). Dried mint leaves were purchased from a local market in Wasit, Iraq. Folin-Ciocalteu reagent was purchased from Sigma-Aldrich (St. Louis, Mo., U.S.A.). Sodium carbonate was purchased from Merck (Darmstadt, Germany). Nutrient ager and peptone water were purchased from Sigma-Aldrich (St. Louis, Mo., U.S.A.).

\subsection{Preparation of aqueous mint leaf extract}

Dried mint leafs were grounded into powder by using lab grinder. The powder obtained was used as the raw material for the following experiments to prepare crude extract. Next, $1 \mathrm{~g}$ of mint leafs powder were added to $10 \mathrm{ml}$ of distilled water at 1:10 (solids: solvent). The mixture was stirred on a hot plate magnetic stirrer (L-81, LABINCO, Netherlands) for $15 \mathrm{~min}$ at $100{ }^{\circ} \mathrm{C}$. Subsequently, the extract was filtered through Whatman No 1 filter paper and centrifuged for $10 \mathrm{~min}$ to obtain clear aqueous extract. The supernatant was stored at $-20{ }^{\circ} \mathrm{C}$ until it used.

\subsection{White soft cheese making process}

Prior to cheese processing, a composition analysis of fresh cow's milk was performed by using a milk analyzer (LactoFlash, Funke Gerber, Germany). The milk was poured into a sterile cheese making container and the temperature increased up to $90 \mathrm{C}^{\circ}$ for 2 sec. After cooling down the milk to $45 \mathrm{C}^{\circ}, 1,2$ and $3 \%(\mathrm{v} / \mathrm{v} \%)$ concentrations of AMLE were added to it. Then $0.004 \%$ of Rennet (Microbial Meito Rennet, Meito Sangyo Co. Ltd, Tokyo, Japan) was added to the milk. After $30 \mathrm{~min}$ incubation at room temperature, clots were transferred onto sterile mesh for dehydration and incubated for $2 \mathrm{~h}$ at room temperature. After completion of the dehydration steps, final cutting and molding of clots was performed. Cheeses were transferred into sterile containers and storage in $4^{\circ} \mathrm{C}$ for two days for the following experiments.

\subsection{Determination of total phenolic compounds}

Total phenolic compounds of mint leafs extract and white soft cheese samples were determined according to the method reported by Pereira et al. [9]. Room temperature mixture was carried out at a test tube by mixing $100 \mu \mathrm{l}$ of the sample with $10 \mathrm{ml}$ of distilled water and $0.5 \mathrm{ml}$ of Folin-Ciocalteau reagent. The mixture allowed to stand for $3 \mathrm{~min}$ before addition of $1.5 \mathrm{ml}$ of sodium carbonate (20\%) and 6.9 of distilled water. Subsequently, the mixtures were stirred and incubated at $40{ }^{\circ} \mathrm{C}$ for $30 \mathrm{~min}$. The optical density at $765 \mathrm{~nm}$ was measured for the mixtures using a spectrophotometer (UV-1100 Spectrophotometer, EMCLAB, GmbH, Germany). Gallic acid was used as a standard and the results of mint leafs extract were stated as milligram gallic acid equivalents per gram of sample (mg GAE / g raw material). For white cheese samples, the results were stated as milligram gallic acid equivalents per 100 gram of cheese sample (mg GAE / $100 \mathrm{~g}$ ).

\subsection{Microbial analysis}

One $\mathrm{g}$ from the core of each cheese sample was aseptically cut and placed in $9 \mathrm{ml}$ of $0.1 \%$ buffered peptone water and homogenized. The resulting homogenates were serially diluted with peptone water $(0.1 \%)$ and the diluted samples were used for microbial determination. Plate count agar was used for the enumeration of total plate counts using the pour plate method. Then, the plates were incubated at $37^{\circ} \mathrm{C}$ for $24 \mathrm{~h}$ and counted. The microbial counts in this study were expressed as colony forming units (CFU) per gram of sample.

\subsection{Sensory evaluation}

The sensory program was split into five phases evaluating taste, texture, color, flavor and overall acceptance. Test phase was submitted to potential judges with the aim to evaluate the basic tastes of cheese samples. The cheese samples utilized in the texture tests were cut to obtain suitable cubes $(1.5 \mathrm{~cm}$ size $)$. This phase aimed to measuring main cheese texture characteristics (surface roughness, surface moisture, elasticity and hardness). Applicants were recruited among people living in the province of Wasit; most of them were employed at University of Wasit (10 potential candidates). All the candidates were briefed on the scope of the sensory evaluation technique and the procedures of each test; previous results were presented and discussed before running any new test.

\subsection{Data analysis}

Data obtained were analyzed using SPSS software (SPSS, Inc., Chicago, IL, USA). Analysis of variance (ANOVA) was performed and significant differences between mean values were determined by Duncan's test. The results obtained were expressed as means \pm standard deviation. P-values $<0.05$ were considered as statistically significant. 


\subsection{Milk composition}

\section{Results And Discussion}

The gross composition of milk is shown in Table 1. Milk content of Fat, SNF, protein and lactose were $4.57,8.31,3.07$ and $1.03 \%$ respectively. The basic composition of bovine milk from different regions is fairly similar with some differences depends on genetic and environmental factors [10]. Fats are involved in cheese yield (per kilogram of milk) and firmness, as well as in the color and flavor of dairy products [11]. Protein composition and content of bovine milk has received increased interest in recent years because an increasing proportion of milk is used for manufactured products such as cheese [12].

Table 1. Composition of fresh milk used in the present study to prepare white soft cheese.

\begin{tabular}{ll}
\hline Item & Value (\%) \\
\hline Fat & $4.57 \pm 0.43$ \\
SNF & $8.31 \pm 0.12$ \\
Protein & $3.07 \pm 0.04$ \\
Lactose & $4.76 \pm 0.01$ \\
\hline
\end{tabular}

Values are given as mean \pm standard deviation. SNF: solid not fat.

\subsection{Total phenolics content of white soft cheese prepared with AMLE}

Table 2 shows the total phenolics content of white soft cheese samples prepared with different concentrations $(1 \%, 2 \%, 3 \%)$ of AMLE. As seen in this Table, the total phenolics content of white soft cheese increased significantly $(\mathrm{P}<0.05)$ after the addition of AMLE as compared to the control white soft cheese sample (white soft cheese prepared without AMLE). The control white soft cheese had significantly the lowest phenolic content ( $24.5 \mathrm{mg}$ GAE / $100 \mathrm{~g}$ cheese) compared to the white soft cheese samples prepared with different concentrations of AMLE. Among white soft cheese samples prepared with different concentrations of AMLE, white soft cheese containing 3\% AMLE had significantly the higher phenolics content (96.0 mg GAE / $100 \mathrm{~g}$ cheese). These results indicated that the addition of AMLE significantly improved the phenolics content of white soft cheese. Similar results were reported for cheese samples supplemented with different concentrations of rosemary extract [13].

Table 2. Total phenolic compounds of white soft cheese samples incorporated with different concentrations

\begin{tabular}{ll}
\multicolumn{2}{c}{$(1 \%, 2 \%, 3 \%)$ of mint leaf extract. } \\
\hline Sample & Total phenolic content (mg GAE/ 100 g cheese) \\
\hline Control & $24.5 \pm 0.7^{\mathrm{a}}$ \\
White soft cheese + 1\% AMLE & $76.5 \pm 2.1^{\mathrm{b}}$ \\
White soft cheese + 2\% AMLE & $82.5 \pm 2.1^{\mathrm{b}}$ \\
White soft cheese + 3\% AMLE & $96.0 \pm 4.2^{\mathrm{c}}$ \\
\hline
\end{tabular}

Values are given as mean \pm standard deviation. Values with different letters within the same column are significantly different $(p<0.05)$. AMLE: aqueous mint leaf extract.

\subsection{Total microbial count of white soft cheese prepared with AMLE}

Statistical analysis of the effect of different concentrations of AMLE on the dependent variable according to CFU/g in white cheese showed that the overall concentrations of AMLE had a significant effect on the growth of total bacterial counts $(P<0.05)$. ANOVA test showed that the growth of total bacterial counts in white soft cheese, with concentrations of 1,2 and $3 \%$ of AMLE was significantly decreased $(P<0.05)$ comparing with the control cheese (Fig. 1 and Table 3).

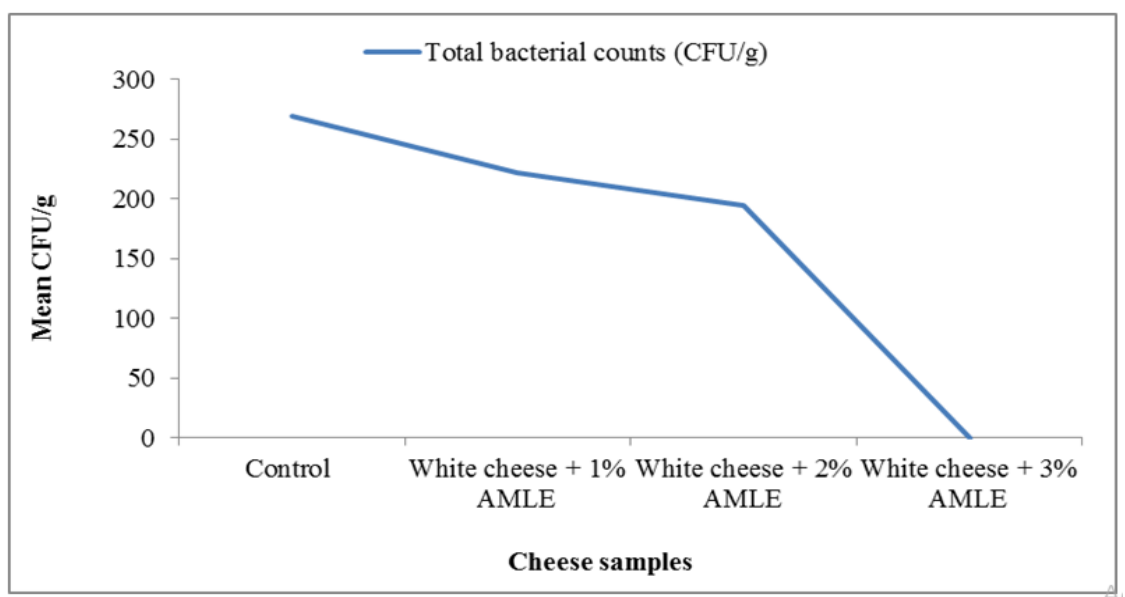

Fig. 1. Effect of different levels (1,2 and 3\%) of AMLE (aqueous mint leaf extract) on total bacterial counts $(\mathrm{CFU} / \mathrm{g})$ in white soft cheese. 
The components M. spicata are different from other species of Mentha genus, the main difference is the presence of Carvone, which represent the higher percentage (about 70\%) of the essential oil [14]. Other study demonstrated that Carvone, Limonene and Menthone were reported as the most important components in M. spicata [15]. From the previous studies conducted with respect to the antibacterial effects of $M$. spicata extracts, it can be concluded that Carvone and Limonene compounds in this herb have an antibacterial effect [16]. Furthermore, it had been reported that Transcaryophyllene has a very strong antimicrobial activity against Gram-positive bacteria [17]. Overall, the biological activity of plant extract is associated with their chemical components, which are depend on plant genotype and affected by a number of factors, including environmental, geographical and agricultural circumstances [18].

Table 3. Total bacterial counts in white soft cheese samples incorporated with different concentrations $(1 \%, 2 \%$, $3 \%$ ) of mint leaf extract.

\begin{tabular}{ll}
\hline Sample & Total bacterial counts (CFU/g) \\
\hline Control & $245 \pm 49.5^{\mathrm{a}}$ \\
White soft cheese + 1\% AMLE & $205 \pm 35.4^{\mathrm{a}}$ \\
White soft cheese + 2\% AMLE & $180 \pm 28.3^{\mathrm{a}}$ \\
White soft cheese + 3\% AMLE & - \\
\hline
\end{tabular}

Values are given as mean \pm standard deviation. Values followed by the same letter within a column indicate no significant difference. AMLE: aqueous mint leaf extract. CFU: colony forming units. - : no growth was observed.

\subsection{Sensory evaluation of white soft cheese prepared with AMLE}

Table 4 shows the results for the sensory attributes evaluation of white soft cheese samples prepared with different concentrations $(1 \%, 2 \%, 3 \%)$ of AMLE. In this study, the parameters tested were taste, texture, color, flavor and overall acceptability. The sensory analysis reveals that there is no significant effect of AMLE addition on sensory attributes of white soft cheese. The white soft cheese prepared with different concentrations of AMLE was not significantly differed from the control cheese, except for the flavor. The white soft cheese prepared with $1 \%$ and $2 \%$ of AMLE had higher scores of flavor and was more acceptable as compared to the control cheese. However, increasing AMLE concentration did not significantly affect flavor scores of the cheese produced. In general, no significant differences were observed in the overall acceptability of all types of cheese and all were acceptable by panelists. Other findings mention that herbs like oregano and rosemary essential oils demonstrated a protective effect against lipid oxidation and fermentation in flavored cheese prepared with cream cheese base [19].

Table 4. Sensory profile of white soft cheese samples incorporated with different concentrations $(1 \%, 2 \%, 3 \%)$ of mint leaf extract.

\begin{tabular}{|c|c|c|c|c|c|}
\hline \multirow[t]{2}{*}{ Sensory attributes } & \multirow[t]{2}{*}{ Score limit } & \multicolumn{4}{|c|}{ White soft cheese samples incorporated with different concentrations of AMLE } \\
\hline & & Control & $1 \%$ & $2 \%$ & $3 \%$ \\
\hline Taste & $1-10$ & $7.40 \pm 0.5^{\mathrm{a}}$ & $7.40 \pm 1.1^{\mathrm{a}}$ & $7.40 \pm 2.0^{\mathrm{a}}$ & $7.60 \pm 1.1^{\mathrm{a}}$ \\
\hline Texture & $1-10$ & $6.60 \pm 1.1^{\mathrm{a}}$ & $7.60 \pm 1.5^{\mathrm{a}}$ & $7.80 \pm 1.3^{\mathrm{a}}$ & $8.20 \pm 0.8^{\mathrm{a}}$ \\
\hline Color & $1-10$ & $7.00 \pm 0.8^{\mathrm{a}}$ & $7.00 \pm 0.7^{\mathrm{a}}$ & $7.40 \pm 2.1^{\mathrm{a}}$ & $8.00 \pm 1.0^{\mathrm{a}}$ \\
\hline Flavor & $1-10$ & $6.20 \pm 1.1^{\mathrm{a}}$ & $8.00 \pm 1.0^{\mathrm{b}}$ & $8.00 \pm 1.7^{\mathrm{b}}$ & $6.80 \pm 0.8^{\mathrm{ab}}$ \\
\hline Overall acceptability & $1-10$ & $7.00 \pm 0.7^{\mathrm{a}}$ & $7.80 \pm 0.8^{\mathrm{a}}$ & $7.80 \pm 1.6^{\mathrm{a}}$ & $7.80 \pm 0.8^{\mathrm{a}}$ \\
\hline
\end{tabular}

Values are given as mean \pm standard deviation. Values with the same letters in the same row are not significantly different. AMLE: aqueous mint leaf extract.

\section{Conclusion}

This study showed that the addition of aqueous mint leaf extract improved the phenolics content of white soft cheese. Aqueous mint leaf extract concentrations had a significant effect on the total microbial growth in white soft cheese. The addition of aqueous mint leaf extract did not affect the overall acceptance of the final product. These findings suggest that the white soft cheese fortified with aqueous mint leaf extract is a functional food that can exert antibacterial and antioxidant properties.

\section{Acknowledgments}

The authors wish to express their thanks to Wasit University for the facilities given for this research work. 


\section{References}

[1] A. Bhattacharya, P. Sood \& V. Citovsky, The roles of plant phenolics in defence and communication during Agrobacterium and Rhizobium infection, Molecular plant pathology, 11(5), 2010, 705-719.-19.

[2] C. Rice-Evans, N. Miller and G. Paganga, Antioxidant properties of phenolic compounds, Trends in plant science, 2(4), 152-159.

[3] R. Löliger, The Use of Antioxidants in Food, in O.I. Aruoma and B. Halliwell (Ed.), Free Radicals and Food Additives, (London: Tayler \& Francis, 1991) 121-150.

[4] M. Serafini, G. Maiani and A. Ferro-Luzzi, Alcohol-free red wine enhances plasma antioxidant capacity in humans, The Journal of Nutrition, 128(6), 1998, 1003-1007.

[5] I. W. Liaw, H. Eshpari, P. S. Tong and M. A. Drake, The impact of antioxidant addition on flavor of Cheddar and Mozzarella whey and Cheddar whey protein concentrate, Journal of food science, 75(6), 2010, 559-569.

[6] R. F. Almeida-Doria and M. A. Regitano-d'arce, Antioxidant activity of rosemary and oregano ethanol extracts in soybean oil under thermal oxidation, Food Science and Technology (Campinas), 20(2), 2000, 197-203.

[7] M. Bandyopadhyay, R. Chakraborty and U. Raychaudhuri, A process for preparing a natural antioxidant enriched dairy product (Sandesh), LWT-Food Science and Technology, 40(5), 2007, 842-851.

[8] M. H. Moosavy, S. Esmaeili and E. Mostafavi, Antibacterial effect of Mentha spicata essential oil on Listeria monocytogenes in traditional lighvan cheese, Journal of Food Safety, 33(4), 2013, 509-514.

[9] V. P. Pereira, F. J. Knor, J. C. R. Vellosa and F. L. Beltrame, Determination of phenolic compounds and antioxidant activity of green, black and white teas of Camellia sinensis (L.) Kuntze, Theaceae, Revista Brasileira de Plantas Medicinais, 16(3), 2014, 490498.

[10] D. L. Palmquist, A. D. Beaulieu \& D. M. Barbano, Feed and animal factors influencing milk fat composition1, Journal of dairy science, 76(6), 1993, 1753-1771.

[11] A. Delacroix-Buchet \& G. Lamberet, Sensorial properties and typicity of goat dairy products. In International Association of Goat. Proceedings of the International Conference of Goats, Tours, France, 2000, $559-63$.

[12] E. J. De Peters \& J. P. Cant, Nutritional Factors Influencing the Nitrogen Composition of Bovine Milk: A Review1, Journal of Dairy Science, 75(8), 1992, 2043-2070.

[13] H. M. F. El-Din, E. I. Ghita, S. M. A. Badran, A. S. Gad and M. M. El-Said, Manufacture of low fat UF-soft cheese supplemented with rosemary extract (as natural antioxidant), Journal of American Science, 6 (10), 2010, 570-579.

[14] V. De Feo, A. I. Ricciardi, D. Biscardi, and F. Senatore, Chemical composition and antimicrobial screening of the essential oil of Minthostachys verticillata (Griseb.) Epl. (Lamiaceae), Journal of Essential Oil Research, 10, 1998, 61-65.

[15] M. Soković, J. Glamočlija, P.D. Marin, D. Brkić and L. J. Van Griensven, Antibacterial effects of the essential oils of commonly consumed medicinal herbs using an in vitro model, Molecules, 15(11), 2010, 7532-7546.

[16] R. Naigre, P. Kalck, C. Roques, I. Roux and G. Michel, Comparison of antimicrobial properties of monoterpenes and their carbonylated products, Planta medica, 62(03), 1996, 275-277.

[17] A. P. Delamare, I. T. Moschen-Pistorello, L. Artico, L. Atti-Serafini and S. Echeverrigaray, Antibacterial activity of the essential oils of Salvia officinalis L. and Salvia triloba L. cultivated in South Brazil, Food chemistry, 100(2), 2007, 603-608.

[18] K. Aggarwal, S. Khanuja, A. Ahmad, T. R Santha Kumar, V. Gupta and S. Kumar, Antimicrobial activity profiles of the two enantiomers of limonene and carvone isolated from the oils of Mentha spicata and Anethum sowa, Flavour and Fragrance Journal, 17(1), 2002, 59-63.

[19] R. H. Olmedo, V. Nepote, and N.R. Grosso, Preservation of sensory and chemical properties in flavoured cheese prepared with cream cheese base using oregano and rosemary essential oils, LWT-Food Science and Technology, 53(2), 2013, 409-417. 